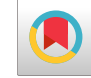

\title{
An Investigation into the Prevalence and Treatment of Oral Mucositis After Cancer Treatment
}

\author{
Farnoosh Razmara ${ }^{1}$ and Mina Khayamzadeh (iD) ${ }^{2,}$ \\ ${ }^{1}$ Department of Oral and Maxillofacial Surgery, Craniomaxillofacial Research Center, Tehran University of Medical Sciences, Tehran, Iran \\ ${ }^{2}$ Department of Oral and Maxillofacial Medicine, Tehran University of Medical Sciences, International Campus, Tehran, Iran \\ "Corresponding author: Assistance Professor, Department of Oral and Maxillofacial Medicine, Tehran University of Medical Sciences, International Campus, Tehran, Iran. \\ Email: mkhayamzadeh@yahoo.com
}

Received 2018 December 29; Revised 2019 July 16; Accepted 2019 August 10.

\begin{abstract}
Context: Oral mucositis is one of the most common side effects of cancer treatments, which affects all the patients receiving radiation treatment. Oral and oropharyngeal mucosa are involved in the treatment process. Also known as stomatitis, oral mucositis is one of the most common side effects of cancer treatments, which is associated with cancer chemotherapy and radiotherapy. It is estimated that this complication affects about $40 \%$ of the patients. Mucositis occurs when cancer treatments collapse the epithelial cells. Some of the main symptoms of mucositis include pain, discomfort, and inability to consume food or fluids. Severe mucositis may delay the treatment and hinder the efficacy of cancer treatment. Patients suffering from reduced immunity and damaged oral mucosa are prone to mouth infections. Several treatment agents can be used to reduce the lesions of mucositis. Given the fact that natural herbal remedies have fewer side effects than synthetic drugs, they are commonly used to treat mucositis.

Evidence Acquisition: In this regard, the Best Practice Information Sheet aims at not only providing evidence on the prevention and treatment of oral mucositis but also at evaluating the efficacy of natural agents for managing oral mucositis, particularly in patients with cancer.

Results: Although these agents have been used to reduce the severity of intolerable mucositis pain, there is yet no definitive treatment. Some agents are not cost-effective and some involve adverse side effects.

Conclusions: The present study showed that new traditional alternative medicines are promising alternatives for treating cancerinduced mucositis. It is recommended that dentists use these agents in clinical practice.
\end{abstract}

Keywords: Cancer, Chemotherapy, Oral Mucositis, Treatment, Radiotherapy

\section{Context}

Known as one of the most debilitative side effects of cancer treatment, mucositis affects the whole gastrointestinal tract (GIT). The oral cavity is said to be the most frequent location for mucositis. Patients who undergo chemotherapy or radiotherapy may experience mucositis in the head and neck. Accordingly, $20 \%$ to $40 \%$ of patients receiving conventional chemotherapy suffer from this condition (1). Concomitant chemotherapy and targeted agents may increase the risk of mucositis. Given the solid and liquid food dysphagia, dysarthria, and odynophagia, oral lesions are associated with the decreased quality of life and depression in patients, especially those who need percutaneous endoscopic gastrostomy tube insertion (2). Moreover, mucositis lesions can pave the way for opportunistic infections, make cancer treatment a complex process, and prolong the admission. Given the fact that mu- cositis provides dose-limiting toxicity for chemotherapy and radiotherapy, it can impact the survival rate $(3,4)$.

Oral mucositis can be defined as the inflammation of the mucosa in the oral cavity. It occurs when cancer treatments collapse the epithelial cells. It is associated with chemotherapy and radiation in cancer treatment $(5,6)$. Despite the fact that oral mucositis is not a common condition, it can occur secondary to chemotherapy of various solid tumors. Oral mucositis is a debilitating complication in patients with cancer (7). Some of the most frequent symptoms of oral mucositis are atrophy, erythema, ulceration, and swelling of the mucosa. The thinning of the oral tissues can lead to erythema. It can be attributed to oral mucositis. Ulcerations occur when these tissues become thinner. It can cause several problems, including the increased risk of infection due to open sores in the mucosa, pain, increased risk of local and systemic infections, bleeding, nutritional problems, inability to eat, etc. It signifi- 
cantly affects the patient's quality of life and can be doselimiting (7).

\subsection{Overview of Mucositis Pathophysiology}

Given the recent developments in mucositis research, several factors affecting mucosal injury have been emphasized. Researchers have proposed a 5-phase chronological process for this condition, including initial damage response, signal amplification, initiation, ulceration, and the healing stage (5). Also known as mucosa or the mucous membrane, mucosal tissue has the ability to lines all body passages such as the respiratory and alimentary tracts. Oral mucosa is one of the most sensitive parts of the body, which is highly prone to chemotherapy and radiation. Mucositis occurs when gastrointestinal (GI) mucosa is subjected to cytotoxic agents. These agents can damage cellular Deoxyribonucleic acid (DNA) and kill the cells. Accordingly, reactive oxygen species (ROS) is associated with tissue injury, negatively triggering a cascade of inflammatory pathways (8). Ortiz et al. reported that mitochondrial oxidation is associated with radiation and sometimes causes mitochondrial dysfunction (9).

As the condition progresses, significant inflammatory mediator up-regulation may emerge. This may be attributed to the activation of the nuclear factor- $\kappa \mathrm{B}$ (NF$\kappa \mathrm{B})$ pathway. The signaling and amplification phase is expected to emerge, during which NF- $\kappa$ B promotes the expression of multiple pro-inflammatory molecules, including inducible nitric oxide synthase, cyclooxygenase-2 (COX-2), Tumor necrosis factor- $\alpha$ (TNF- $\alpha$ ), and Interleukin$1 \beta$ pro-inflammatory cytokine (pro-IL-1 $\beta$ ). The feedback amplification of the NF- $\kappa$ B-dependent signaling pathway is ensured during this phase (8). Moreover, mitochondrial ROS production increases inflammation by activating a multi-protein cytoplasmic complex. NACHT, LRR, and PYD domains-containing protein 3 (NLRP3) may assembly activate caspase-1 and cleaves pro-cytokines such as pro-IL-1 $\beta$, pro-IL-18, and pro-IL-33 $(9,10)$, leading to ulceration. Therefore, the NF- $\kappa$ B pathway, mitochondrial dysfunction, and subsequent NLRP3 activation contribute to the development of oral mucositis. The whole inflammatory process can be triggered by positive feedback loops. This may prolong the tissue.

In the initiation phase, patients may gradually develop erythema focal areas (11). As the progression of mucositis begins to prolong, mucosal integrity collapses. When atrophic changes begin to appear in the GI mucosa, the tissue is damaged and the stem cells are destroyed. By infiltrating and activating the macrophages, bacterial colonization at the mucosa may further trigger the inflammation, which may emerge almost 2 weeks after the treatment (8). Originating from bacterial colonization, cell wall residues penetrate the submucosa. Macrophages are triggered and activated in the submucosa (12). This is mainly characterized by prolonged admission, severe pain, the need for parenteral nutrition, and the increased risk of morbidity and mortality. The final phase of mucositis pathobiology is the healing process. Epithelial cells began to migrate, grow, and differentiate form a wound (12). One of the other common side effects of anticancer chemotherapy is intestinal mucositis, which affects the small intestines. This condition is characterized by the production of ROS and the amplification of inflammatory signals. The signals originate mainly from anticancer drugs or radiation. Lee et al. (8) reported that the first histological effect was an increase in apoptosis. A day after the treatment, a 7-fold increase in apoptosis in intestinal crypts was reported. However, 3 days after the treatment, it was found that the intestinal villous area and crypt length reduced (3).

Another common side effect of mucositis is that healthy intestine tissue is damaged due to radiation (13). Recently, it was shown that tongue radiation can contribute to intestinal damage. It was also found that the small intestines of irradiated animals may be affected by mucositis. Decreased villus height and morphological alterations are supposed to emerge in these animals. They are associated with substantial intestinal architecture changes (14). The oral irradiation of rats was mainly associated with mitochondrial oxidative stress, bio-energetic impairment, and subsequent NLRP3 activation in the development of radiotherapy-induced gut toxicity. Overall, these processes further damaged the small intestines.

\section{Evidence Acquisition}

Several methods have been proposed to measure and quantify the changes occurring in the oral epithelium. In this regard, the World Health Organization has developed a scale that is now the most commonly used scale in research. In addition, the most widely used scale for the clinical evaluation of mucositis is the Common Terminology Criteria for Adverse Events (CTCAE), which is proposed by the United States National Cancer Institute. This scale deals with the need for treatment measures, the ability for oral intake, and symptoms (15).

One of the main aims of this comprehensive study is to constitute a generalized review around novel published literature for presenting the situation of oral mucositis prevalence and treatment. Consequently, 4 major medical databases, including The EMBASE, PubMed, The Cochrane Library, Medline and some extra related journals were surveyed and the appropriate records were chosen by high precision. A total of 302 records were recognized at 
first. One hundred and seventeen records were removed due to similarity and duplication and, then, 185 records maintained. After the screening of the records and their subjects, 74 extra unrelated records were excluded. Then, 111 qualified full-text articles were selected, but 27 records were excluded due to some specific reasons. Finally, after adding 6 related records found in the available resources, 90 high-quality records were selected (Figure 1).

\section{Results}

\subsection{Risk Factors for Mucositis}

According to the reports, several factors can influence the frequency and severity of mucositis. Factors influencing the likelihood of mucositis include poor oral hygiene before and during chemotherapy, the type of tumor involved, age, the nutritional condition of the patient, and the maintenance of kidney and liver function (16). The reports showed that the type of cytostatic agents used such as antimetabolites and purine analogs may increase the likelihood of developing mucositis. It is worth mentioning that such drugs are reportedly associated with $40 \%$ to $60 \%$ of the incidences of oral mucositis (15). In addition, methotrexate may worsen the lesions of oral mucositis. However, the findings showed that asparaginase and carmustine do not contribute to the development of mucositis (17). Almost $40 \%$ to $70 \%$ of the patients receiving standard chemotherapy regimens are likely to develop mucositis (17). Factors influencing the appearance of mucositis are concomitant treatment with radiotherapy and bone marrow transplantation and the frequency of administration.

\subsection{Clinical Characteristics of Mucositis}

Mucositis appears as thinning of the oral mucosa and finally results in ulceration. It is mainly associated with swallowing disability and severe pain. It can worsen the quality of life and hinder the proper functioning of the patients $(15,17)$. The radiotherapy is interrupted, chemotherapy is stopped, and analgesics become compulsory. Although various agents have been used, there is still no validated guideline for the treatment of oral mucositis, particularly in patients with head and neck cancers (HNC) (17). The experiments have indicated that 7 to 10 days after chemotherapy, patients may suffer from severe pain and discomfort. In some cases, opioids and dietary changes are recommended. However, 2 to 3 weeks after the infusion of the drug, the symptoms of mucositis abate. Candida albicans can develop some infections. Patients with prolonged neutropenia are more likely to develop these infections. In some cases, the infections can be life-threatening (17). Some of the most common bacteria taken from blood are Streptococcus mitis and Streptococcus oralis, which lead to respiratory distress syndrome (17).

\subsection{Treatment}

Despite the fact that the biological nature of the oral mucositis complicates the management process, there are several strategies to minimize the adverse effects of anticancer treatment, some of which include dose reduction and other both therapeutic and preventive measures. It is not possible to stop mucositis from occurring, but there are measures before beginning radiation. The traditional management of oral mucositis required the patients' compliance and education, hydration, nutritional support, use of saline rinses, topical and systemic pain relief, and infection surveillance and treatment (18). In some cases, palliative treatments, including palifermin and benzydamine have also been used (19). Cancer therapy-related oral mucositis is usually regarded as the most debilitating complication for chemotherapy and radiation treatment (7). The present paper reviews new treatment methods for oral mucositis. Therefore, this paper aims at investigating the main treatment options for oral mucositis.

\subsection{Management of Oral Mucositis}

There are some strategies managing oral mucositis, including preventative measures and treatment approaches. Several studies have been carried out to find an effective treatment for mucositis or its associated pain. However, it is often difficult to manage the toxicities of treatment. Here are some strategies for managing oral mucositis (11):

- Low-level laser therapy (LLLT)

- Rinse with analgesics of opioids

- Topical palliative agents (Cathodal, Episil, GelClair, and MuGard)

- Oral decontamination

- Antioxidant agents with thiol groups

- Cryotherapy

- Epithelial growth factors

- Others anti-inflammatory agents (Benzydamine HCI, Misoprostol, Glutamine)

By eliminating the presence of any irritants to the oral mucosa, improved oral hygiene can be used to reduce the risk and severity of oral mucositis. Given the fact that tissue injury activates nociceptive receptors and increases pain along with the underlying tissue damage, systemic analgesics are also recommended (20). There is a wide variety of topical palliative agents, including Caphosol, Episil, GelClair, and MuGard, which can be used to treat mucositis. These agents can alleviate pain and improve the patient's quality of life. The inability to effectively coat all areas is one of the disadvantages of using topical agents. Nar- 


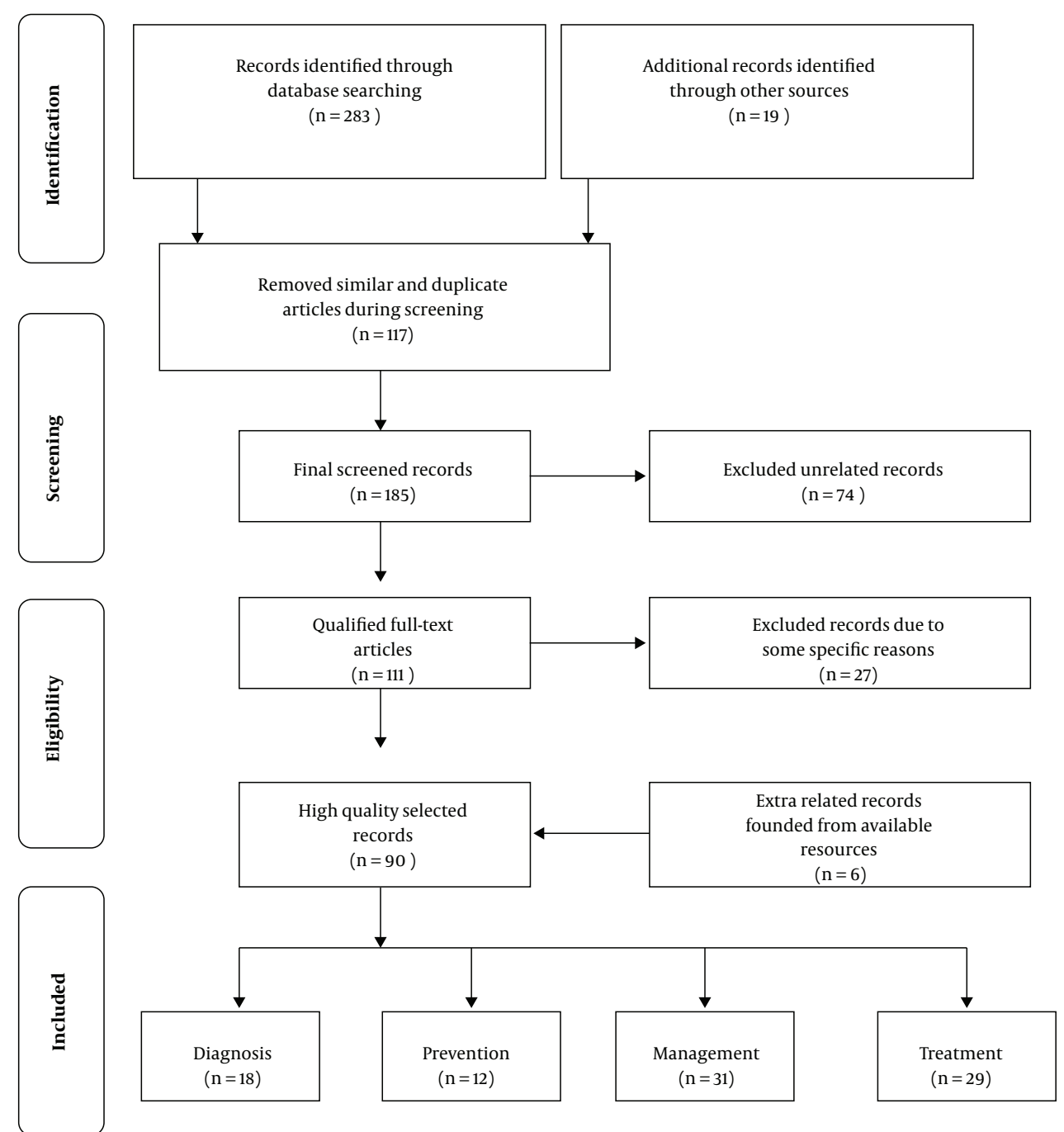

Figure 1. The selection mechanism schedule of records relevant to the present study in accordance with the PRISMA technique

cotic analgesia is often necessary for patients with mucositis (11,21-23). Pain is significantly associated with mucositis. Measures that may help alleviate the pain include a topical morphine solution, magic mouthwash preparations, and other useful analgesics (11). An oral rinse containing doxepin apparently plays an important role in alleviating acute oral mucositis pain (24). The traditional patch is another type of topical agent that consists of a potent, fast, and short-acting synthetic opioid analgesic. According to studies, transdermal fentanyl results in itching, mild dizziness, gastrointestinal reactions, etc. (25). Furthermore, oral decontamination can significantly prevent mucositisinduced ulceration. Silva et al. (26) have recently investigated a soft pastille formulation. The findings showed that this formulation can facilitate accurate drug administration. On the other hand, chlorhexidine is an efficient antiseptic agent that can be used (27). However, these drugs cannot efficiently reduce the severity or incidence of mucositis (28).

Many antioxidant agents have been investigated in order to prevent or reduce the severity of mucositis. N-acetyl can stimulate glutathione synthesis and scavenge free radicals. Moreover, N-acetyl cysteine (NAC) limits the activation of NF- $\kappa \mathrm{B}$, leading to an increase in the inflammatory response. A double-blind trial reported that N-acetyl cysteine can significantly reduce the incidence of severe oral mucositis (29). According to the findings, reduced proliferative capacity of oral epithelial cells may contribute to the 
mucositis pathogenesis. For this purpose, a wide variety of growth factors have been investigated in order to manage oral mucositis. As noted earlier, it remains to be seen whether palifermin will be indicated for use among oral cancer patients because it is associated with severe side effects. It is expensive and needs careful administration (30). There are also some other growth factors that require further studies so that they can be approved for use in the treatment of mucositis (31). Smad7 (Mothers against decapentaplegic homolog 7) was first recognized as a TGF- $\beta$ (Transforming growth factor- $\beta$ ) superfamily signaling antagonist. It has recently attracted the attention of a wide variety of researchers (32). Overall, Smad7 can be an efficient tool for the treatment of oral mucositis $(32,33)$.

According to studies, LLLT reduces the incidence of mucositis and limits the symptoms of oral mucositis. Particularly, patients undergoing hematopoietic stem cell transplantation and myeloablative chemotherapy have reported this issue $(5,34,35)$. Despite the fact that the mechanisms behind these advantages have not yet been fully understood, there is still evidence that LLLT can reduce cytokine levels (11). However, in some cases, LLLT can result in undesirable tumor behaviors and/or treatment responses (36).

Furthermore, some other approaches have been proposed for the treatment and prevention of intestinal mucositis, including probiotics, probiotic-derived factors, and plant extracts and preparations. Yeung et al. (37) reported that Lactobacillus acidophilus, Lactobacillus rhamnosus (Lcr35), Lactobacillus casei, and Bifidobacterium bifidum (LaBi), if taken on a daily basis, can limit pro-inflammatory, cytokines diarrhea, and jejunal villi damages. Moreover, a prospective open-labeled randomized trial in Sweden found that the administration of Lactobacillus rhamnosus could reduce grade 3 or 4 diarrhea and minimize the duration of admission (38). An et al. (38) did not have blinding and placebo control. In addition, a large double-blinded randomized trial in Italy aimed at investigating the effect of probiotics in the prevention of diarrhea (39).

It should be pointed out that Traditional Chinese Medicine (TCM) provides empirical herbal formulas that can be used to treat mouth ulcers and stomatitis. However, there is not strong evidence for these treatments (40). Moreover, there is no standard concept for such treatments. The conventional oncologists believe that they are not acceptable treatment strategies. Western complementary medicine has proposed several herbal treatment approaches, some of which are Eriodictyon crassifolium, Flos caryophylli, Citrus limon, Oleum olivae, Hippophae rhamnoides, Aloe vera, Potentilla erecta, Malva spps, Chimonanthus salicifolius, Gentianae radix, Menyanthes folium, Salvia officinalis, Matriciana camomilla, Calendula officinalis,
Hamamelis virginiana, Commiphora molmol, Myrtilli fructus, Althaea spps, Cetraria islandica, Linum usitatissimum, Carica papaya, Centaurii herba, and Gentianae radix. Some of the most commonly used herbs are Salvia officinalis and Matriciana camomilla (41-45). However, it was found that the chamomile could not prove efficient in patients with chemotherapy-induced mucositis (46). The different agents used in the management of mucositis are provided in Table 1.

The lesions of oral mucositis can be classified into 3 categories, including atrophic, erythematous, or ulcerative lesions. Ulcerative lesions of oral mucositis are characterized by severe pain, the increased risk of severe infections, oral bleeding, compromised oral and pharyngeal function, and risk of admission. Oral mucositis is graded based on nutritional state and clinical aspects. There are various scales for grading the mucositis. In this regard, the World Health Organization proposed oral mucositis toxicity, which is typically used in daily practice. This simple scale is capable of measuring both subjective and objective symptoms of oral mucositis (Table 2). A vast number of treatment agents have been developed, the most commonly used of which include LLLT, oral decontamination, local anesthetic agents, anti-inflammatory agents, oral health care, benzydamine hydrochloride rinse, etc. Despite the fact that these agents have been utilized to alleviate the severity of mucositis pain, no definitive treatment has been developed yet. Some agents are not costeffective and some involve adverse side effects. Thus, some agents such as olive oil, curcumin, aloe vera, and honey are being used to reduce the morbidity of mucositis and minimize the side effects compared with synthetic drugs. In addition, one can have access to these agents without any prescription 50. On the other hand, this study aimed at assessing the related literature on the natural agents used to prevent and manage oral mucositis.

\subsection{Clinical Trials}

Table 3 summarizes the clinical trials. Most of the trials showed that natural agents are capable of reducing the severity of oral mucositis compared with placebo or synthetic agents (53-72). Bardy et al. (64) and Hawley et al. (60) reported that Manuka honey does not affect lesions $(60,64)$. Accordingly, Sahebjamee et al. (65) found that Aloe Vera gel (AV gel) failed to reduce pain or heal lesions. It could not improve the quality of life of 58 patients with cancer. For this purpose, further studies are needed to investigate the effect of AV gel on oral mucositis lesions (65). The reports showed that according to studies, the natural treatment proved to have better patient compliance with fewer side effects. Given the fact that Manuka honey trig- 


\begin{tabular}{|c|c|c|c|}
\hline Type & Agent & Laboratory Test & Results \\
\hline Mouthwash & Traumeel S & $\begin{array}{l}\text { A randomized clinical trial of Traumeel } S \text { for the } \\
\text { treatment of stomatitis in children undergoing } \\
\text { stem cell transplantation }(47)\end{array}$ & $\begin{array}{l}\text { The severity and duration of } \\
\text { chemotherapy-induced stomatitis were reduced. }\end{array}$ \\
\hline \multirow{2}{*}{ Topical } & MuGard & $\begin{array}{l}\text { Multi-institutional trial to evaluate the efficacy of a } \\
\text { mucoadhesive hydrogel (MuGard) in mitigating } \\
\text { oral mucositis symptoms in patients being treated } \\
\text { with chemoradiation therapy for HNC ( } 21)\end{array}$ & $\begin{array}{l}\text { MuGard lessened the severity of developing } \\
\text { mucositis and pain. }\end{array}$ \\
\hline & Fentanyl & $\begin{array}{l}\text { Efficacy of transdermal fentanyl for the treatment } \\
\text { of oral mucositis pain caused by radiotherapy in } \\
\text { patients with esophageal squamous cell carcinoma } \\
(25)\end{array}$ & $\begin{array}{l}\text { Fentanyl could alleviate the pain caused by } \\
\text { radiotherapy. }\end{array}$ \\
\hline $\begin{array}{l}\text { Decontamination and } \\
\text { prevention }\end{array}$ & Nystatin & $\begin{array}{l}\text { Efficacy of chlorhexidine and nystatin rinses in the } \\
\text { prevention of oral complications in leukemia and } \\
\text { bone marrow transplantation (48) }\end{array}$ & $\begin{array}{l}\text { Nystatin rinse has not been found to be effective in } \\
\text { reducing the severity of chemotherapy-induced } \\
\text { mucositis. }\end{array}$ \\
\hline \multirow{3}{*}{ Antioxidants } & Amifostine & $\begin{array}{l}\text { Chemotherapy-and radiotherapy-induced oral } \\
\text { mucositis: Review of preventive strategies and } \\
\text { treatment (49) }\end{array}$ & $\begin{array}{l}\text { Amifostine may reduce the frequency of severe } \\
\text { esophagitis in patients undergoing concomitant } \\
\text { chemotherapy and radiotherapy for non-small cell } \\
\text { lung cancer. }\end{array}$ \\
\hline & N-acetyl cysteine (NAC) & $\begin{array}{l}\mathrm{N} \text {-acetyl cysteine for the prevention of oral } \\
\text { mucositis in hematopoietic sct: A double-blind, } \\
\text { randomized, placebo-controlled trial (29) }\end{array}$ & $\begin{array}{l}\text { NAC significantly reduced the incidence of severe } \\
\text { oral mucositis (grades 3-4) after high-dose } \\
\text { chemotherapy and no patient in the NAC group } \\
\text { developed grade } 4 \text { mucositis. }\end{array}$ \\
\hline & Matricaria Chamomilla & $\begin{array}{l}\text { Prospective evaluation of a chamomile mouthwash } \\
\text { for the prevention of 5-FU-induced oral mucositis } \\
(46)\end{array}$ & $\begin{array}{l}\text { Later phase III trials of Matricaria chamomilla have } \\
\text { failed to conclude that the chamomile given in } \\
\text { mouthwash formulations is effective in patients } \\
\text { with chemotherapy-induced mucositis. }\end{array}$ \\
\hline Growth factors & $\begin{array}{l}\text { Keratinocyte growth } \\
\text { factor }(\mathrm{KGF})\end{array}$ & $\begin{array}{l}\text { Palifermin for oral mucositis after intensive } \\
\text { therapy for hematologic cancers ( } 30)\end{array}$ & $\begin{array}{l}\text { KGF significantly reduced the incidence of grades } 3 \\
\text { and } 4 \text { oral mucositis in patients with hematologic } \\
\text { malignancies. }\end{array}$ \\
\hline Anti-inflammatory & Glutamine & $\begin{array}{l}\text { Oral glutamine reduces the duration and severity } \\
\text { of stomatitis after cytotoxic cancer chemotherapy } \\
\text { (51) }\end{array}$ & $\begin{array}{l}\text { In two small, randomized studies prophylactic } \\
\text { glutamine mouthwashes significantly reduced the } \\
\text { incidence, severity, and duration of oral mucositis } \\
\text { in patients undergoing radiotherapy or } \\
\text { chemotherapy, respectively. }\end{array}$ \\
\hline $\begin{array}{l}\text { Locally applied } \\
\text { nonpharmacological }\end{array}$ & $\begin{array}{l}\text { Low-level laser therapy } \\
\text { (LLLT) }\end{array}$ & $\begin{array}{l}\text { Phase III trial of low-level laser therapy to prevent } \\
\text { oral mucositis in head and patients with neck } \\
\text { cancer treated with concurrent chemoradiation } \\
(52)\end{array}$ & $\begin{array}{l}\text { Preventive LLLT in patients with head and neck } \\
\text { squamous cell carcinoma (HNSCC) receiving } \\
\text { chemoradiotherapy is an effective tool for reducing } \\
\text { the incidence of grades 3-4 oral mucositis. }\end{array}$ \\
\hline
\end{tabular}

\begin{tabular}{ll}
\hline \multicolumn{2}{l}{ Table 2. Grading of Oral Mucositis (World Health Organization) } \\
\hline Level & Explanation \\
\hline $\mathbf{0}$ & No changes \\
$\mathbf{1}$ & Erythema \pm soreness \\
$\mathbf{2}$ & Erythema, ulcers, patients can swallow solid food \\
$\mathbf{3}$ & Patients cannot swallow solid food (ulcers with extensive erythema) \\
$\mathbf{4}$ & The nourishment for patients is not possible \\
\hline
\end{tabular}

gered nausea and vomiting, patients could not tolerate it $(60,64)$.

\section{Conclusion}

Mucositis appears when cancer treatments collapse the epithelial cells. This makes the mucosal tissue prone to ulceration and infection. Mucositis reportedly affects $40 \%$ to $80 \%$ of patients receiving chemotherapy. Oral mucositis is mostly observed in patients, who receive chemoradiation to treat HNC (1). According to the literature, the capacity of several synthetic agents has been investigated in order to heal the lesion. However, these agents have not been approved yet. How these agents interact with other drugs is still a major concern. According to Somerfield Criteria, the above-mentioned agents have failed to offer sufficient evidence in most cases. Natural remedies can be used 


\begin{tabular}{|c|c|c|c|c|c|}
\hline Type of Study & Natural Agents & Way of Use & Cancer Type & Way of Treatment & Reference \\
\hline \multirow{5}{*}{ RCT } & $20 \mathrm{~mL}$ of honey & Topical & HNC & Radiotherapy (RT) & (53) \\
\hline & $\begin{array}{l}\text { Honey and a mixture of } \\
\text { honey, olive oil-propolis } \\
\text { extract, and beeswax }\end{array}$ & Topical & $\begin{array}{c}\text { Acute lymphoblastic } \\
\text { leukemia }\end{array}$ & Computed tomography (CT) & $(54)$ \\
\hline & $\begin{array}{l}50 \mathrm{~mL} \text { solution of turmeric, } \\
\text { thrice daily for five days }\end{array}$ & Topical & HNC & $\mathrm{CT} / \mathrm{RT}$ induced $\mathrm{OM}$ & (55) \\
\hline & Yashtimadhu Ghrita, honey & Topical and oral (PO) & HNC & RCT & (56) \\
\hline & $\begin{array}{l}\text { Sage tea-thyme-peppermint } \\
\text { hydrosol }\end{array}$ & PO & - & CT & (57) \\
\hline \multirow{2}{*}{ Single-blinded, RCT } & Honey with lignocaine & Topical & HNC & RT & $(58)$ \\
\hline & $\begin{array}{l}\text { Turmeric, } 10 \mathrm{~mL} \text { swishing in } \\
\text { the mouth for } 2 \text { minutes, } 6 \\
\text { times a day i.e. } 1 \text { hours. prior } \\
\text { to radiation, } 1,2,4 \text {, and } 6 \\
\text { hours after radiation } \\
\text { therapy and once before } \\
\text { going to bed }\end{array}$ & $\mathrm{PO}$ & HNC & RT & (59) \\
\hline \multirow{4}{*}{ Double-blind, RCT } & $5 \mathrm{~mL}$ of Manuka honey & Topical, PO & HNC & RT & (60) \\
\hline & $\begin{array}{l}\text { Syrup-like solution. } 20 \text { g of } \\
\text { instant coffee in the Honey, } \\
\text { (HC) group, and "300 grams } \\
\text { of honey" for the Honey }(\mathrm{H}) \\
\text { group }\end{array}$ & PO & HNC & CT & (61) \\
\hline & $\begin{array}{l}\text { OLE, } 3 \text { - } 4 \text { times a day for } 14 \\
\text { days }\end{array}$ & PO & Leukemia & CT & (62) \\
\hline & $\begin{array}{l}\text { A. millefolium } 4 \text { times a day } \\
\text { for } 14 \text { days }\end{array}$ & $\mathrm{PO}$ & - & CT & (63) \\
\hline Double-blind RCT & $\begin{array}{l}\text { Manuka honey } 20 \mathrm{~mL} 4 \\
\text { times daily for } 6 \text { weeks }\end{array}$ & Topical & HNC & RT & (64) \\
\hline Triple-blind, RCT & Aloe Vera & $\mathrm{PO}$ & HNC & RT & (65) \\
\hline $\begin{array}{l}\text { Randomized single-blind } \\
\text { Trial }\end{array}$ & $\begin{array}{l}\text { RJ (3 g/day), Three times a } \\
\text { day }\end{array}$ & Topical & HNC & CRT & (66) \\
\hline \multirow{2}{*}{ Double-blind clinical trial } & PE, 10 drops of oral rinse & $\mathrm{PO}$ & Colon/rectum cancers & CT & (67) \\
\hline & $\begin{array}{l}\text { OLE, } 3 \text { - } 4 \text { times a day for } 14 \\
\text { days from the start of CT }\end{array}$ & $\mathrm{PO}$ & HNC & CT & (62) \\
\hline $\begin{array}{l}\text { Randomized triple-blind } \\
\text { trial }\end{array}$ & $\begin{array}{l}15 \mathrm{~mL} \text { of propolis } \\
\text { mouthwash three times a } \\
\text { day for } 5 \text { weeks }\end{array}$ & $\mathrm{PO}$ & HNC & RT & (68) \\
\hline Randomized trial & $\begin{array}{l}\text { Cryotherapy made with } \\
\text { chamomile infusion }\end{array}$ & $\mathrm{PO}$ & - & CT & (69) \\
\hline Prospective trial & $\begin{array}{l}\text { 2\% Calendula mouthwash, } \\
\text { three times per day for } 6 \\
\text { weeks }\end{array}$ & $\mathrm{PO}$ & HNC & RT & (70) \\
\hline Phase II open-label trial & $\begin{array}{l}\text { The mucoadhesive gel } \\
\text { containing propolis } 5.0 \% \\
\text { three times a day for } 2 \text { weeks }\end{array}$ & Topical & Oral Cancer & RT & (71) \\
\hline \multirow{2}{*}{ Pilot study } & $\begin{array}{l}10 \text { drops of Curcumal twice } \\
\text { per day in a mouthwash }\end{array}$ & Mouthwash & Pediatric cancer & Doxorubicin- containing CT & (72) \\
\hline & $\begin{array}{l}\text { Curcumin mouthwash } \\
0.004 \% \text {, thrice daily in } 1: 5 \\
\text { dilution for } 1 \text { minute for } 20 \\
\text { minutes }\end{array}$ & $\mathrm{PO}$ & HNC & RCT & (59) \\
\hline
\end{tabular}

to reduce the symptoms of mucositis (46).

Honey, as a natural agent, offers many medicinal properties, including wound healing, tissue repair, and therapeutic properties. Some of the other prominent properties of honey are high osmolality and low $\mathrm{pH}$. Honey is capable of reducing mucosal irritation because it can in- crease nitric oxide concentration in lesions and decrease prostaglandin concentration. It is famous mostly for its anti-inflammatory and antioxidant properties. Given the fact that Manuka pollen contains methylglyoxal, it can offer strong antibacterial properties $(59,73)$. According to some trials, honey showed great capacity in reducing ul- 
cerations and lesions of oral mucositis $(54,58,61)$. Higher levels of hydrogen peroxide can damage the cells and diluted honey proved to have even more adverse effects, reducing the bioactivity of the honey $(60,73)$. As Bardy et al. (64) and Hawley et al. (60) stated, Manuka honey failed to prove a safe agent for patients and it caused nausea and vomiting. In order to further investigate the association between honey and the incidence of caries in patients with oral mucositis, it is necessary to perform a long-term follow-up and RCT (74). Over-dosage of AV could be associated with severe diarrhea and drug interactions should also be kept in mind mainly with corticosteroids and thiazide diuretics, which would result in electrolyte imbalance $(55,59,72,75)$.

There are several promising alternatives to synthetic treatment for oral mucositis lesions after RT/CT, some of which are Glycyrrhiza glabra, indigo wood root, placental extract, Calendula officinalis, olive oil, PE, propolis, etc. For instance, olive oil is capable of treating several ulcerative lesions such as recurrent aphthous ulcers since it has anti-inflammatory, antioxidant, antibacterial properties. Given the fact that it is capable of healing the oral mucositis lesions by decreasing pro-inflammatory cytokines such as IL-1 $\beta$ and TNF- $\alpha$ in patients with cancer (62), olive oil has attracted the attention of researchers. As a natural nontoxic sticky resinous material, Propolis is used for anti-inflammatory purposes in folk medicine. Caffeic acid phenyl ethyl ester (CAPE) is a strong antioxidant that can prevent the proliferation of neoplastic cells $(68,71)$. As an important medicinal herb with antioxidant, anti-inflammatory properties, Yashti-Madhu (Glycyrrhiza glabra) has recently gained importance (56). Peppermint essence (PE) can reduce the side effects of cancer treatment (67). The placental extract can facilitate wound healing and reduce the severity of oral mucositis lesions (75). Royal jelly (RJ), mainly composed of vitamins, proteins, sugars, lipids, amino acids, and minerals, is necessary for the development of the queen honeybee. The findings have proved the antitumor, antioxidant, anti-inflammatory, antibacterial, and anti-allergic wound healing properties of $\mathrm{RJ}$ (66). Some Chinese herbs have been found to play a key role in reducing oral mucositis lesions. According to the findings, Calendula officinalis offers antioxidant, antifungal, anti-inflammatory, and antibacterial properties 70. Achillea millefolium, a member of Asteraceae family, can provide antibacterial, anti-inflammatory, and anti-spasmodic properties (63). Chamomile is composed of coumarins, flavonoids, terpenoids, alpha-bisabolol, chamazulene, bisabolol oxides, spirometers, and mucilage. According to the findings, Chamomile is mainly known for antioxidant, mildly astringent, anticancer, anti-inflammatory, and antifungal wound healing properties. Dos Reis et al. (69) re- ported that Chamomile has positive effects on oral mucositis lesions.

Despite the fact that steroids are one of the most commonly used treatments for oral mucositis, it is expensive and involves adverse side effects. Raeessi et al. showed that coffee and honey are promising agents for reducing oral mucositis lesions because they can accelerate the healing process and enhance tolerance (61). Given the fact that green Propolis gel contains flavonoids, such as galangin and artepillin C, it proved to have anti-inflammatory, antimicrobial, antifungal, and antioxidant properties. Compared with alcoholic solution of benzydamine $\mathrm{HCl}$, it could efficiently reduce the severity of oral mucositis after 17th session of RT (76). The efficacy of chlorhexidine gluconate gel $0.2 \%$ was also evaluated. The results showed that it cannot improve the lesions. Besides, some of the prominent disadvantages of chlorhexidine gluconate gel $0.2 \%$ were bitter taste, discoloration of teeth, and unpleasant sensation (77). This alternative can heal wounds and reduce secondary infections. However, further research is recommended. Djavid et al. showed that LLLT can reduce grades 3 and 4 mucositis, but further research is needed to investigate the efficacy of this modality. Unfortunately, LLLT is not cost-effective and cannot be approved (78). Future studies need to examine the interactions between drugs and agents.

The present study showed that new traditional alternative medicines are promising alternatives for treating cancer-induced mucositis. It is recommended that dentists use these agents in clinical practice. Finally, further research is needed to investigate the properties of herbal medicines so that it is possible to treat oral mucositis and reduce the pain and lesions.

\section{Acknowledgments}

None declared.

\section{Footnotes}

Authors' Contribution: The authors contribute equally. Conflict of Interests: There is no conflict of interest. Financial Disclosure: It is not declared by the authors. Funding/Support: There is not any financial support for this study.

\section{References}

1. Itoh Y, Kubota S, Kawamura M, Nomoto Y, Murao T, Yamakawa $\mathrm{K}$, et al. A multicenter survey of stage $\mathrm{T} 1$ glottic cancer treated 
with radiotherapy delivered in 2.25-Gy fractions in clinical practice: An initial 5-year analysis. Nagoya J Med Sci. 2016;78(4):399-406. doi: 10.18999/nagjms.78.4.399. [PubMed: 28008195]. [PubMed Central: PMC5159465].

2. Sonis ST. Oral mucositis in head and neck cancer: Risk, biology, and management.Am Soc Clin OncolEduc Book. 2013. doi:10.1200/EdBook_AM.2013.33.e236. [PubMed: 23714511].

3. Campos MI, Campos CN, Aarestrup FM, Aarestrup BJ. Oral mucositis in cancer treatment: Natural history, prevention and treatment. Mol Clin Oncol. 2014;2(3):337-40. doi: 10.3892/mco.2014.253. [PubMed: 24772297]. [PubMed Central: PMC3999143].

4. Kyriakopoulos CE, Braden AM, Kolesar JM, Eickhoff JC, Bailey HH, Heideman J, et al. A phase I study of tivantinib in combination with temsirolimus in patients with advanced solid tumors. Invest New Drugs. 2017;35(3):290-7. doi: 10.1007/s10637-016-0418-8. [PubMed: 28004284]. [PubMed Central: PMC5809175].

5. Alvarino-Martin C, Sarrion-Perez MG. Prevention and treatment of oral mucositis in patients receiving chemotherapy. J Clin Exp Dent. 2014;6(1):e74-80. doi: 10.4317/jced.51313. [PubMed: 24596640]. [PubMed Central: PMC3935910].

6. Rohani B, Pourfar K, Pourshahidi H, Ebrahimi SH. Oral manifestation of hematologic malignancies. Jundishapur Sci Med J. 2015;14:477-85.

7. Jadaud E, Bensadoun R. Low-level laser therapy: A standard of supportive care for cancer therapy-induced oral mucositis in head and neck cancer patients? Laser Ther. 2012;21(4):297-303. doi: 10.5978/islsm.12-RE-01. [PubMed: 24511199]. [PubMed Central: PMC3882349].

8. Lee CS, Ryan EJ, Doherty GA. Gastro-intestinal toxicity of chemotherapeutics in colorectal cancer: The role of inflammation. World J Gastroenterol. 2014;20(14):3751-61. doi: 10.3748/wjg.v20.i14.3751. [PubMed: 24744571]. [PubMed Central: PMC3983434].

9. Ortiz F, Acuna-Castroviejo D, Doerrier C, Dayoub JC, Lopez LC, Venegas $\mathrm{C}$, et al. Melatonin blunts the mitochondrial/NLRP3 connection and protects against radiation-induced oral mucositis. J Pineal Res. 2015;58(1):34-49. doi: 10.1111/jpi.12191. [PubMed: 25388914].

10. Escames G, Lopez LC, Garcia JA, Garcia-Corzo L, Ortiz F, AcunaCastroviejo D. Mitochondrial DNA and inflammatory diseases. Hum Genet. 2012;131(2):161-73. doi: 10.1007/s00439-011-1057-y. [PubMed: 21735170].

11. Villa A, Sonis ST. Mucositis: Pathobiology and management. Curr Opin Oncol. 2015;27(3):159-64. doi: 10.1097/CCO.0000000000000180. [PubMed: 25774860].

12. Khaw A, Logan R, Keefe D, Bartold M. Radiation-induced oral mucositis and periodontitis - proposal for an inter-relationship. Oral Dis. 2014;20(3):e7-18. doi: 10.1111/odi.12199. [PubMed: 24147592].

13. Cameron S, Schwartz A, Sultan S, Schaefer IM, Hermann R, RaveFrank M, et al. Radiation-induced damage in different segments of the rat intestine after external beam irradiation of the liver. Exp Mol Pathol. 2012;92(2):243-58. doi: 10.1016/j.yexmp.2011.11.007. [PubMed: 22227376].

14. Fernandez-Gil B, Moneim AE, Ortiz F, Shen YQ, Soto-Mercado V, Mendivil-Perez $\mathrm{M}$, et al. Melatonin protects rats from radiotherapyinduced small intestine toxicity. PLoS One. 2017;12(4). e0174474. doi: 10.1371/journal.pone.0174474. [PubMed: 28403142]. [PubMed Central: PMC5389624].

15. Chaveli-Lopez B. Oral toxicity produced by chemotherapy: A systematic review. J Clin Exp Dent. 2014;6(1):e81-90. doi: 10.4317/jced.51337. [PubMed: 24596641]. [PubMed Central: PMC3935911].

16. Chaveli Lopez B, Gavalda Esteve C, Sarrion Perez MG. Dental treatment considerations in the chemotherapy patient. J Clin Exp Dent. 2011;3:e31-42. doi: 10.4317/jced.3.e31.

17. Worthington HV, Clarkson JE, Bryan G, Furness S, Glenny AM, Littlewood $\mathrm{A}$, et al. Interventions for preventing oral mucositis for patients with cancer receiving treatment. Cochrane Database Syst Rev. 2011;(4). CD000978. doi: 10.1002/14651858.CD000978.pub5. [PubMed: 21491378].
18. Cirillo N, Vicidomini A, McCullough M, Gambardella A, Hassona Y, Prime SS, et al. A hyaluronic acid-based compound inhibits fibroblast senescence induced by oxidative stress in vitro and prevents oral $\mathrm{mu}$ cositis in vivo. J Cell Physiol. 2015;230(7):1421-9. doi:10.1002/jcp.24908. [PubMed: 25536474].

19. Lalla RV, Sonis ST, Peterson DE. Management of oral mucositis in patients who have cancer. Dent Clin North Am. 2008;52(1):61-77. viii. doi: 10.1016/j.cden.2007.10.002. [PubMed: 18154865]. [PubMed Central: PMC2266835].

20. EOCC. European oral care in cancer group oral care guidance and support. 2017. Report No.: Guidelines-Online-Version- v2-1.

21. Allison RR, Ambrad AA, Arshoun Y, Carmel RJ, Ciuba DF, Feldman E, et al. Multi-institutional, randomized, double-blind, placebocontrolled trial to assess the efficacy of a mucoadhesive hydrogel (MuGard) in mitigating oral mucositis symptoms in patients being treated with chemoradiation therapy for cancers of the head and neck. Cancer. 2014;120(9):1433-40. doi: 10.1002/cncr.28553. [PubMed: 24877167]. [PubMed Central: PMC4164024].

22. Quinn B. Efficacy of a supersaturated calcium phosphate oral rinse for the prevention and treatment of oral mucositis in patients receiving high-dose cancer therapy: A review of current data. Eur J Cancer Care (Engl). 2013;22(5):564-79. doi: 10.1111/ecc.12073. [PubMed: 23731197].

23. Raphael MF, den Boer AM, Kollen WJ, Mekelenkamp H, Abbink FC, Kaspers GJ, et al. Caphosol, a therapeutic option in case of cancer therapy-induced oral mucositis in children? Results from a prospective multicenter double blind randomized controlled trial. Support Care Cancer. 2014;22(1):3-6. doi: 10.1007/s00520-013-2015-0. [PubMed: 24197056].

24. Leenstra JL, Miller RC, Qin R, Martenson JA, Dornfeld KJ, Bearden JD, et al. Doxepin rinse versus placebo in the treatment of acute oral mucositis pain in patients receiving head and neck radiotherapy with or without chemotherapy: A phase III, randomized, doubleblind trial (NCCTG-N09C6 [Alliance]). J Clin Oncol. 2014;32(15):1571-7. doi: 10.1200/JCO.2013.53.2630. [PubMed: 24733799]. [PubMed Central: PMC4026580].

25. Xing SZ, Zhang Y. Efficacy and safety of transdermal fentanyl for the treatment of oral mucositis pain caused by chemoradiotherapy in patients with esophageal squamous cell carcinoma. Support Care Cancer. 2015;23(3):753-9. doi: 10.1007/s00520-014-2419-5. [PubMed: 25179692].

26. Silva FC, Marto JM, Salgado A, Machado P, Silva AN, Almeida AJ. Nystatin and lidocaine pastilles for the local treatment of oral mucositis. Pharm Dev Technol. 2017;22(2):266-74. doi: 10.1080/10837450.2016.1221424. [PubMed: 27499389].

27. Bey A, Ahmed SS, Hussain B, Devi S, Hashmi SH. Prevention and management of antineoplastic therapy induced oral mucositis. NatlJMaxillofac Surg. 2010;1(2):127-34. doi: 10.4103/0975-5950.79214. [PubMed: 22442583]. [PubMed Central: PMC3304209].

28. Cardona A, Balouch A, Abdul MM, Sedghizadeh PP, Enciso R. Efficacy of chlorhexidine for the prevention and treatment of oral mucositis in cancer patients: A systematic review with meta-analyses. J Oral Pathol Med. 2017;46(9):680-8. doi: 10.1111/jop.12549. [PubMed: 28075506].

29. Moslehi A, Taghizadeh-Ghehi M, Gholami K, Hadjibabaie M, Jahangard-Rafsanjani Z, Sarayani A, et al. N-acetyl cysteine for prevention of oral mucositis in hematopoietic SCT: A double-blind, randomized, placebo-controlled trial. Bone Marrow Transplant. 2014;49(6):818-23. doi: 10.1038/bmt.2014.34. [PubMed: 24614837].

30. Vitale KM, Violago L, Cofnas P, Bishop J, Jin Z, Bhatia M, et al. Impact of palifermin on incidence of oral mucositis and healthcare utilization in children undergoing autologous hematopoietic stem cell transplantation for malignant diseases. Pediatr Transplant. 2014;18(2):211-6. doi: 10.1111/petr.12192. [PubMed: 24823628].

31. Yuan A, Sonis S. Emerging therapies for the prevention and treatment of oral mucositis. Expert Opin Emerg Drugs. 2014;19(3):343-51. doi: 10.1517/14728214.2014.946403. [PubMed: 25102771]. 
32. Han G, Bian L, Li F, Cotrim A, Wang D, Lu J, et al. Preventive and therapeutic effects of Smad7 on radiation-induced oral mucositis. Nat Med. 2013;19(4):421-8. doi: 10.1038/nm.3118. [PubMed: 23475202]. [PubMed Central: PMC3780964].

33. Touchefeu Y, Montassier E, Nieman K, Gastinne T, Potel G, Bruley des Varannes S, et al. Systematic review: the role of the gut microbiota in chemotherapy- or radiation-induced gastrointestinal mucositis - current evidence and potential clinical applications. Aliment Pharmacol Ther. 2014;40(5):409-21. doi: 10.1111/apt.12878. [PubMed: 25040088].

34. Oberoi S, Zamperlini-Netto G, Beyene J, Treister NS, Sung L. Effect of prophylactic low level laser therapy on oral mucositis: A systematic review and meta-analysis. PLoS One. 2014;9(9). e107418. doi: 10.1371/journal.pone.0107418. [PubMed: 25198431]. [PubMed Central: PMC4157876].

35. Allan E, Barney C, Baum S, Kessling T, Diavolitsis VM, Blakaj D, et al. Low-level laser therapy and laser debridement for management of oral mucositis in patients with head and neck cancer receiving chemotherapy and radiation. Int J Radiat Oncol Biol Phys. 2016;94(4):883. doi:10.1016/j.ijrobp.2015.12.066.

36. Sonis ST, Hashemi S, Epstein JB, Nair RG, Raber-Durlacher JE. Could the biological robustness of low level laser therapy (Photobiomodulation) impact its use in the management of mucositis in head and neck cancer patients. Oral Oncol. 2016;54:7-14. doi: 10.1016/j.oraloncology.2016.01.005. [PubMed: 26852286].

37. Yeung CY, Chan WT, Jiang CB, Cheng ML, Liu CY, Chang SW, et al. Amelioration of chemotherapy-induced intestinal mucositis by orally administered probiotics in a mouse model. PLoS One. 2015;10(9). e0138746. doi: 10.1371/journal.pone.0138746. [PubMed: 26406888]. [PubMed Central: PMC4583404].

38. An J, Ha EM. Combination therapy of lactobacillus plantarum supernatant and 5-fluouracil increases chemosensitivity in colorectal cancer cells. J Microbiol Biotechnol. 2016;26(8):1490-503. doi: 10.4014/jmb.1605.05024. [PubMed: 27221111].

39. Guarino A, Guandalini S, Lo Vecchio A. Probiotics for prevention and treatment of diarrhea.JClin Gastroenterol.2015;49 Suppl1:S37-45. doi: 10.1097/MCG.0000000000000349. [PubMed: 26447963].

40. Pottel L, Lycke M, Boterberg T, Pottel H, Goethals L, Duprez F, et al. Echium oil is not protective against weight loss in head and neck cancer patients undergoing curative radio(chemo)therapy: A randomised-controlled trial.BMC Complement Altern Med.2014;14:382. doi: 10.1186/1472-6882-14-382. [PubMed: 25293388]. [PubMed Central: PMC4200132]

41. Meyer-Hamme G, Beckmann K, Radtke J, Efferth T, Greten HJ, Rostock $\mathrm{M}$, et al. A survey of chinese medicinal herbal treatment for chemotherapy-induced oral mucositis. Evid Based Complement Alternat Med. 2013;2013:284959. doi: 10.1155/2013/284959. [PubMed: 24285975]. [PubMed Central: PMC3830834].

42. Liu Z, Xi J, Schroder S, Wang W, Xie T, Wang Z, et al. Chimonanthus nitens var. Salicifolius aqueous extract protects against 5 -fluorouracil induced gastrointestinal mucositis in a mouse model. Evid Based Complement Alternat Med. 2013;2013:789263. doi: 10.1155/2013/789263. [PubMed: 24367389]. [PubMed Central: PMC3866771].

43. Sencer SF, Zhou T, Freedman LS, Ives JA, Chen Z, Wall D, et al. Traumeel $S$ in preventing and treating mucositis in young patients undergoing SCT: A report of the Children's Oncology Group. Bone Marrow Transplant. 2012;47(11):1409-14. doi: 10.1038/bmt.2012.30. [PubMed: 22504933]. [PubMed Central: PMC4008329].

44. Braga FT, Santos AC, Bueno PC, Silveira RC, Santos CB, Bastos JK, et al. Use of Chamomilla recutita in the prevention and treatment of oral mucositis in patients undergoing hematopoietic stem cell transplantation: A randomized, controlled, phase ii clinical trial. Cancer Nurs. 2015;38(4):322-9. doi: 10.1097/NCC.0000000000000194. [PubMed: 25232958].

45. Elkerm Y, Tawashi R. Date palm pollen as a preventative intervention in radiation- and chemotherapy-induced oral mucositis: A pilot study. Integr Cancer Ther. 2014;13(6):468-72. doi:
10.1177/1534735414547110. [PubMed: 25148841]

46. Zakaria S. Natural remedies target different therapeutic pathways in oral mucositis induced by cancer chemo or radiotherapy. Am J Phy tomed Clin Therapeut. 2017;5(1). doi:10.21767/2321-2748.100318.

47. Grech D, Velagala J, Dembek DJ, Tabaac B. Critical literature review of the homeopathic compound traumeel for treatment of inflammation. Pharmacol Pharm. 2018;9(3):67-83. doi: 10.4236/pp.2018.93006.

48. Darwish AM, Salama MA, Basiouny NS, Arafa NM. Effect of chlorhexidine in prevention of oral lesions in leukemic children receiving chemotherapy. JAm Sci. 2011;7(7):985-96.

49. Moslemi D, Nokhandani AM, Otaghsaraei MT, Moghadamnia Y Kazemi S, Moghadamnia AA. Management of chemo/radiationinduced oral mucositis in patients with head and neck cancer: A review of the current literature. Radiother Oncol. 2016;120(1):13-20. doi 10.1016/j.radonc.2016.04.001. [PubMed: 27113797].

50. Kim JW, Kim MG, Lee HJ, Koh Y, Kwon JH, Kim I, et al. Topical recombinant human epidermal growth factor for oral mucositis induced by intensive chemotherapy with hematopoietic stem cell transplantation: Final analysis of a randomized, double-blind placebo-controlled, phase 2 trial. PLoS One. 2017;12(1). e0168854. doi 10.1371/journal.pone.0168854. [PubMed: 28045958]. [PubMed Central: PMC5207736].

51. Chattopadhyay S, Saha A, Azam M, Mukherjee A, Sur PK. Role of oral glutamine in alleviation and prevention of radiation-induced oral mucositis: A prospective randomized study. South Asian J Cancer. 2014;3(1):8-12. doi:10.4103/2278-330X.126501. [PubMed: 24665438]. [PubMed Central: PMC3961877].

52. Antunes HS, Herchenhorn D, Small IA, Araujo CM, Viegas CM, Cabral E, et al. Phase III trial of low-level laser therapy to prevent oral mucositis in head and neck cancer patients treated with concurrent chemoradiation. Radiother Oncol. 2013;109(2):297-302. doi 10.1016/j.radonc.2013.08.010. [PubMed: 24044799].

53. Amanat A, Ahmed A, Kazmi A, Aziz B. The effect of honey on radiationinduced oral mucositis in head and neck cancer patients. Indian J Palliat Care. 2017;23(3):317-20. doi: 10.4103/IJPC.IJPC_146_16. [PubMed 28827938]. [PubMed Central: PMC5545960].

54. Abdulrhman M, Elbarbary NS, Ahmed Amin D, Saeid Ebrahim R. Honey and a mixture of honey, beeswax, and olive oil-propolis extract in treatment of chemotherapy-induced oral mucositis: A randomized controlled pilot study. Pediatr Hematol Oncol. 2012;29(3):285-92. doi: 10.3109/08880018.2012.669026. [PubMed: 22475306].

55. Saldanha SP. A comparative study to assess the effectiveness of turmeric mouth wash versus saline mouth wash on treatment induced oral mucositis (Tiom) in a selected hospital at Mangalore.J Clin Res Bioeth. 2014;5(6):200. doi: 10.4172/2155-9627.1000200.

56. Das D, Agarwal SK, Chandola HM. Protective effect of Yashtimadhu (Glycyrrhiza glabra) against side effects of radiation/chemotherapy in head and neck malignancies. Ayu. 2011;32(2):196-9. doi: 10.4103/0974-8520.92579. [PubMed: 22408302]. [PubMed Central: PMC3296340].

57. Mutluay Yayla E, Izgu N, Ozdemir L, Aslan Erdem S, Kartal M. Sage tea-thyme-peppermint hydrosol oral rinse reduces chemotherapyinduced oral mucositis: A randomized controlled pilot study. Complement Ther Med. 2016;27:58-64. doi: 10.1016/j.ctim.2016.05.010 [PubMed: 27515877].

58. Khanal B, Baliga M, Uppal N. Effect of topical honey on limitation of radiation-induced oral mucositis: An intervention study. Int $J$ Oral Maxillofac Surg. 2010;39(12):1181-5. doi:10.1016/j.ijom.2010.05.014. [PubMed: 20832243].

59. Rao S, Dinkar C, Vaishnav LK, Rao P, Rai MP, Fayad R, et al. The Indian spice turmeric delays and mitigates radiation-induced oral mucositis in patients undergoing treatment for head and neck cancer: An investigational study. Integr Cancer Ther. 2014;13(3):201-10. doi 10.1177/1534735413503549. [PubMed: 24165896].

60. Hawley P, Hovan A, McGahan CE, Saunders D. A randomized placebo- 
controlled trial of manuka honey for radiation-induced oral mucositis. Support Care Cancer. 2014;22(3):751-61. doi:10.1007/s00520-0132031-0. [PubMed: 24221577].

61. Raeessi MA, Raeessi N, Panahi Y, Gharaie H, Davoudi SM, Saadat A, et al. "Coffee plus honey" versus "topical steroid" in the treatment of chemotherapy-induced oral mucositis: A randomised controlled trial. BMC Complement Altern Med. 2014;14:293. doi: 10.1186/1472-688214-293. [PubMed: 25106776]. [PubMed Central: PMC4150938].

62. Ahmed KM. The effect of olive leaf extract in decreasing the expression of two pro-inflammatory cytokines in patients receiving chemotherapy for cancer. A randomized clinical trial. Saudi Dent J. 2013;25(4):141-7. doi: 10.1016/j.sdentj.2013.09.001. [PubMed: 24371380]. [PubMed Central: PMC3871392].

63. Miranzadeh S, Adib-Hajbaghery M, Soleymanpoor L, Ehsani M. Effect of adding the herb Achillea millefolium on mouthwash on chemotherapy induced oral mucositis in cancer patients: A doubleblind randomized controlled trial. Eur J Oncol Nurs. 2015;19(3):207-13. doi: 10.1016/j.ejon.2014.10.019. [PubMed: 25667123].

64. Bardy J, Molassiotis A, Ryder WD, Mais K, Sykes A, Yap B, et al. A doubleblind, placebo-controlled, randomised trial of active manuka honey and standard oral care for radiation-induced oral mucositis. $\mathrm{Br} J$ Oral Maxillofac Surg. 2012;50(3):221-6. doi:10.1016/j.bjoms.2011.03.005. [PubMed: 21636188]

65. Sahebjamee M, Mansourian A, Hajimirzamohammad M, Zadeh MT, Bekhradi R, Kazemian A, et al. Comparative efficacy of aloe vera and benzydamine mouthwashes on radiation-induced oral mucositis: A triple-blind, randomised, controlled clinical trial. Oral Health Prev Dent. 2015;13(4):309-15. doi: 10.3290/j.ohpd.a33091. [PubMed: 25431805].

66. Yamauchi K, Kogashiwa Y, Moro Y, Kohno N. The effect of topical application of royal jelly on chemoradiotherapy-induced mucositis in head and neck cancer: A preliminary study. Int J Otolaryngol. 2014;2014:974967. doi: 10.1155/2014/974967. [PubMed: 25400667]. [PubMed Central: PMC4221863].

67. Ashktorab T, Yazdani Z, Mojab F, Alavi Majd H, Madani H. [Preventive effects of an oral rinse Peppermint essence on chemotherapyinduced oral mucosistis]. Koomesh. 2010;12(1):8-13. Persian.

68. Javadzadeh Bolouri A, Pakfetrat A, Tonkaboni A, Aledavood SA, Fathi Najafi M, Delavarian Z, et al. Preventing and therapeutic effect of propolis in radiotherapy induced mucositis of head and neck cancers: A triple-blind, randomized, placebo-controlled trial. Iran J Cancer Prev. 2015;8(5). e4019. doi: 10.17795/ijcp-4019. [PubMed: 26634113]. [PubMed Central: PMC4667229].

69. Dos Reis PE, Ciol AE, de Melo NS, Figueiredo PT, Leite AF, Manzi Nde M. Chamomile infusion cryotherapy to prevent oral mucositis induced by chemotherapy: A pilot study. Support Care Cancer. 2016;24(10):4393-8. doi: 10.1007/s00520-016-3279-y. [PubMed: 27189615].
70. Babaee N, Moslemi D, Khalilpour M, Vejdani F, Moghadamnia Y, Bijani A, et al. Antioxidant capacity of calendula officinalis flowers extract and prevention of radiation induced oropharyngeal mucositis in patients with head and neck cancers: A randomized controlled clinical study. Daru. 2013;21(1):18. doi: 10.1186/2008-2231-21-18. [PubMed: 23497687]. [PubMed Central: PMC3623793].

71. Noronha VR, Araujo GS, Gomes RT, Iwanaga SH, Barbosa MC, Abdo EN, et al. Mucoadhesive propolis gel for prevention of radiation-induced oral mucositis. Curr Clin Pharmacol. 2014;9(4):359-64. [PubMed: 24502424].

72. Elad S, Meidan I, Sellam G, Simaan S, Zeevi I, Waldman E, et al. Topical curcumin for the prevention of oral mucositis in pediatric patients: Case series. Altern Ther Health Med. 2013;19(3):21-4. [PubMed: 23709456].

73. Dos Reis PE, Ciol MA, de Melo NS, Figueiredo PT, Leite AF, Manzi Nde M. Chamomile infusion cryotherapy to prevent oral mucositis induced by chemotherapy: A pilot study. Support Care Cancer. 2016;24(10):4393-8. doi: 10.1007/s00520-016-3279-y. [PubMed: 27189615].

74. Parsons E, Begley A, Herst P. Manuka honey mouthwash does not affect oral mucositis in head and neck cancer patients in New Zealand. J Radiother Pract. 2011;11(4):249-56. doi:10.1017/s1460396911000410.

75. Santos-Silva AR, Rosa GB, Eduardo CP, Dias RB, Brandao TB. Increased risk for radiation-related caries in cancer patients using topical honey for the prevention of oral mucositis. Int J Oral Maxillofac Surg. 2011;40(11):1335-6. author reply 1235. doi: 10.1016/j.ijom.2011.05.006. [PubMed: 21700426].

76. Patil K, Guledgud MV, Kulkarni PK, Keshari D, Tayal S. Use of Curcumin mouthrinse in radio-chemotherapy induced oral mucositis patients: A pilot study. J Clin Diagn Res. 2015;9(8):ZC59-62. doi: 10.7860/JCDR/2015/13034.6345. [PubMed: 26436049]. [PubMed Central: PMC4576643].

77. Vras N, En A, Fpcl P, Vr S. Propolis gel versus benzydamine in preventing oral mucositis for patients irradiated in head and neck: A preliminary study. Cancer Reports and Reviews. 2017;1(2). doi: 10.15761/crr.1000112.

78. Diaz-Sanchez RM, Pachon-Ibanez J, Marin-Conde F, RodriguezCaballero A, Gutierrez-Perez JL, Torres-Lagares D. Double-blind, randomized pilot study of bioadhesive chlorhexidine gel in the prevention and treatment of mucositis induced by chemoradiotherapy of head and neck cancer. Med Oral Patol Oral Cir Bucal. 2015;20(3):e378-85. doi: 10.4317/medoral.20338. [PubMed: 25662553]. [PubMed Central: PMC4464927].

79. Abramoff MM, Lopes NN, Lopes LA, Dib LL, Guilherme A, Caran EM, et al. Low-level laser therapy in the prevention and treatment of chemotherapy-induced oral mucositis in young patients. Photomed Laser Surg. 2008;26(4):393-400. doi: 10.1089/pho.2007.2144. [PubMed: 18754720]. 